\title{
Alfabetizar em escola pública de período integral: reflexões a partir da ótica dos sujeitos da prática
}

\author{
Andréia de Souza Grava* \\ Elisabete Ferreira Esteves Campos*
}

\section{Resumo}

Este artigo apresenta considerações sobre pesquisa desenvolvida entre 2017 e 2019 que tratou dos desafios da alfabetização numa escola de período integral, localizada em um município da Grande São Paulo. Estabeleceu-se como objetivo principal analisar as facetas da alfabetização e seus desafios a partir da ótica dos sujeitos da prática. As entrevistas com os(as) participantes basearam-se em Szymanski, favorecendo a expressão de ideias, conceitos e relatando os desafios em relação ao tema. Conclui-se que, na escola pesquisada, a coordenadora pedagógica não se sente legitimada, dificultando o trabalho coletivo. Os(as) docentes participantes não fundamentam suas práticas de alfabetização em estudos teóricos, lançando mão, inclusive, de atividades encontradas na internet. A escola de período integral não é reconhecida como favorecedora dos processos de ensino e aprendizagem e, portanto, da alfabetização.

Palavras-chave: Alfabetização; escola de período integral; professores alfabetizadores.

* Pedagoga, psicopedagoga, mestre em Educação pela Universidade Metodista de São Paulo. Docente na Fundação Santo André - FSA. Membro do Grupo de Pesquisa Políticas de Gestão Educacional e de Formação dos Profissionais da Educação e do Grupo de Estudos Paulo Freire. E-mail: gravadeia72@, gmail.com

** Doutora em Educação pela Universidade de São Paulo-USP. Docente e pesquisadora do Programa de Pós-Graduação em Educação da Universidade Metodista de São Paulo. Líder do Grupo de Pesquisa Políticas de Gestão Educacional e de Formação dos Profissionais da Educação e do Grupo de Estudos Paulo Freire. E-mail: elisabete.campos@metodista.br 


\section{Literacy in full time public school: reflections from the perspective of the subjects of practice}

\section{Abstract}

This article presents considerations about research developed between 2017 and 2019 which addressed the challenges of literacy in a full-time school, located in a municipality of Greater São Paulo. It was established as the main objective to analyze the facets of literacy and its challenges from the perspective of the subjects of practice. The interviews with the participants were based on Szymanski, favoring the expression of ideas, concepts and reporting the challenges in relation to the theme. It is concluded that, in the school surveyed, the pedagogical coordinator does not feel legitimized, hindering collective work. The participating professors do not base their literacy practices on theoretical studies, even using activities found on the Internet. Full-time school is not recognized as favoring teaching and learning processes and, therefore, literacy.

Keywords: Literacy; full-time school; literacy teachers.

\section{Alfabetización en una escuela pública con horario extendido: reflexiones desde la perspectiva de las prácticas}

\section{Resumen}

Este artículo presenta consideraciones sobre la investigación realizada entre 2017 y 2019 que abordó los desafíos de la alfabetización en una escuela de tiempo completo ubicada en un municipio del Gran São Paulo. El objetivo principal fue analizar las facetas de la alfabetización y sus desafíos desde la perspectiva de los sujetos de práctica. Las entrevistas con los participantes se basaron en Szymanski, favoreciendo la expresión de ideas, conceptos y reportando los desafíos relacionados con el tema. Se concluye que, en la escuela estudiada, el coordinador pedagógico no se siente legitimado, dificultando el trabajo colectivo. Los profesores participantes no basan sus prácticas de alfabetización en estudios teóricos, incluso haciendo uso de actividades que se encuentran en Internet. No se reconoce que la escuela a tiempo completo favorezca los procesos de enseñanza y aprendizaje y, por tanto, la alfabetización.

Palabras clave: Alfabetización; escuela de tiempo completo; profesores de alfabetización. 


\section{Introdução}

Este artigo apresenta considerações sobre pesquisa desenvolvida entre 2017 e 2019 que tratou dos desafios da alfabetização numa escola de período integral, localizada em um município da Grande São Paulo. Estabeleceu-se como objetivo principal analisar as facetas da alfabetização e seus desafios a partir da ótica dos(as) participantes da prática.

No Brasil, a preocupação com a aprendizagem de modo geral tem justificado a promulgação de políticas públicas, e a ampliação da jornada escolar anuncia esse propósito, no entanto, ela não abarca todos os alunos e alunas, destinando-se especialmente àqueles(as) que são considerados(as) "vulneráveis" e que frequentam escolas com baixo Índice de Desenvolvimento da Educação Básica - IDEB. Por meio da análise documental, constatou-se o propósito de afastar tais estudantes da violência e marginalidade que assolam a sociedade, como se apenas frequentar a escola por mais tempo fosse a solução. Contudo, o acesso à escola em tempo integral, com uma proposta curricular integrada, pode proporcionar aos grupos populares que frequentam a escola pública maior acesso à cultura, aos conhecimentos científicos, à expressão artística e corporal.

Nesses contextos, a investigação teve como foco os processos e práticas de alfabetização em uma escola de período integral localizada em um município com alto Índice de Desenvolvimento Humano-IDH. Partiu-se da hipótese de que os(as) estudantes dessa escola alcançariam sucesso em seu processo de alfabetização. A definição da pesquisa em escola de período integral justificou-se em função da maior possibilidade de alfabetização de todos(as) os(as) estudantes por estarem mais tempo na escola e terem acesso a um currículo diversificado.

A investigação, portanto, partiu de duas questões básicas: Como a Coordenadora Pedagógica (CP) e os(as) docentes dos três anos iniciais do ensino fundamental percebem os fatores que influenciam a alfabetização na escola de tempo integral?" E, em complemento, "Quais as didáticas e/ou estratégias que esses(as) profissionais adotam para alfabetizar? 
Sabe-se que a dificuldade na leitura e na escrita ocorre em virtude de múltiplos fatores, dos quais destacamos:

a) o conceito de alfabetização e metodologias de ensino assumidas nas escolas;

b) as desigualdades sociais, que limitam o acesso de muitas famílias à cultura letrada e até mesmo às instituições de ensino;

c) vivências e experiências distintas, em quaisquer classes sociais, que podem contribuir ou dificultar a aprendizagem da leitura e da escrita.

Como alerta Charlot (1996), há crianças de famílias com baixo poder econômico que obtêm sucesso na escola, assim como há crianças de famílias de classes econômicas mais elevadas que podem apresentar dificuldades. Por isso, a desigualdade social, embora relevante, não explica todos os casos de sucesso ou fracasso escolar, ou seja, crianças de classe social com menor poder aquisitivo podem ser alfabetizadas.

A heterogeneidade que caracteriza os(as) educandos(as) é também fator relevante para analisar o que ocorre no contexto escolar nos primeiros anos do ensino fundamental, com diferenças em termos sociais, culturais, com variados ritmos de aprendizagem e de relações com o saber (CHARLOT, 1996). Para o autor, há diversas formas de os(as) estudantes relacionarem-se com o saber, atribuindo sentidos e significados distintos para as aprendizagens.

Partindo de tais pressupostos, foram ouvidos(as) os(as) profissionais que atuam nas escolas a fim de identificar como compreendem essa multiplicidade de fatores e como agem pedagogicamente, a partir de tais compreensões, no processo de alfabetização dos(as) estudantes.

Considerou-se, na investigação, os três primeiros anos do ensino fundamental, período em que as crianças devem ter compreendido o sistema de escrita alfabética, lendo e escrevendo com maior proficiência. 


\section{Motivação e relevância social do tema}

Esta pesquisa está fundamentada em autores que abordam a formação integral de estudantes, especialmente em escolas de tempo integral, e naqueles que analisam questões relativas à alfabetização e ao fracasso escolar. Dentre eles, destacamos: Emília Ferreiro, Délia Lerner, Paulo Freire e Miguel Arroyo.

Conforme Gumperz (1991), a transmissão social da alfabetização pelos sistemas educacionais em seu processo de escolarização tem ainda revelado o fracasso dessa alfabetização escolarizada, a qual se diferenciou dos usos diários da leitura e da escrita, pois aquilo que era "ensinado através da alfabetização escolarizada, não mais era parte de uma cultura comum local, de modo que as pessoas comuns tinham menos controle sobre os produtos de sua própria cultura" (p. 43).

Sendo assim, destacamos, sobretudo, a necessidade de se pensar, refletir, (re)construir conhecimentos sobre os elementos que se congregam nesta pesquisa: a alfabetização em escola pública de tempo integral e seus desdobramentos frente ao sucesso da aprendizagem.

Ao considerar que este estudo analisa os processos de alfabetização em escola pública de tempo integral, torna-se necessário apresentar os principais conceitos utilizados que serviram de aporte teórico para este trabalho: a alfabetização, a educação integral em escola de tempo integral e o fracasso escolar.

Desde a publicação da cartilha Caminho Suave, criada pela educadora Branca Alves de Lima, em 1948, até as concepções, metodologias e estudos contemporâneos que consideram os saberes das crianças sobre a leitura e a escrita, o conceito e a prática da alfabetização foram se reconfigurando, pois, com os avanços das pesquisas, é possível afirmar que os métodos e os objetivos de ontem, destinados a alfabetizar as crianças de ontem, não mais funcionam para as crianças de hoje, tampouco para as crianças de amanhã.

A cartilha Caminho Suave, é importante esclarecer, apresentava um método criado pela educadora Branca Alves de Lima (19112001) intitulado "alfabetização pela imagem". Durante algumas 
décadas, foi utilizada como recurso didático e adotada para alfabetizar várias gerações no Brasil, a partir de fins da década de 1940. Como marco editorial e livro oficial de alfabetização do Ministério da Cultura por cerca de cinquenta anos, foram impressos quase 40 milhões de exemplares e 132 edições, e desde o ano de 1995 não é mais o instrumento oficial de alfabetização do País. Mesmo assim, ainda é publicada e continua vendendo em média dez mil exemplares por ano (GARCIA, 2017).

António Nóvoa, reitor honorário da Universidade de Lisboa, em entrevista a Santos e Andretta (2018), jornalistas do informativo on-line Digitais - PUC Campinas, durante a $1^{a}$ Conferência de Educação do Instituto Integral Cultural, realizada em 28 de agosto de 2018, sob o título: "A Metamorfose da Escola", afirmou que na escola do século XXI "[...] o que deve ficar é, sobretudo, o conhecimento, ele é absolutamente central. Ele deve estar adaptado ao que é o conhecimento no século XXI, da maneira como ele está organizado hoje", e o mais importante, de acordo com o pesquisador, é que a "[...] a escola seja capaz de abrir mundos, que possa dar instrumentos às crianças para que elas, em liberdade, possam escolher e que façam os caminhos que quiserem fazer".

Assim, conceitos, métodos e metodologias de alfabetização, fortemente impactados pelo meio sociocultural, foram modificados e continuam se transformando ao longo do tempo, pelas razões já enunciadas, e também devido às descobertas realizadas no campo da Epistemologia Genética de Piaget, que embasaram as pesquisas sobre a Psicogênese da Língua Escrita (FERREIRO; TEBEROSKY, 1986).

As investigações de Emília Ferreiro promoveram uma verdadeira "revolução conceitual", alterando significativamente a compreensão do processo de alfabetização ao evidenciar que os(as) estudantes constroem hipóteses sobre o que está escrito e o que se pode ler. É preciso, então, que as intervenções dos(as) professores(as) ocorram a partir dessas hipóteses, propondo atividades adequadas e desafiadoras que gerem novos conhecimentos. 
Torna-se, portanto, necessário planejar situações que promovam reflexões sobre a escrita, de modo que as crianças possam estabelecer relações entre o que já sabem e o que estão aprendendo. Nesse sentido, a concepção de Ferreiro (2010) apresenta-se como uma metodologia que consolida o aprendido, ao mesmo tempo em que promove um processo de alfabetização que parte das hipóteses dos estudantes para gerar avanços.

Não há dúvidas de que os avanços científicos implicam na formação continuada de professores(as) alfabetizadores(as), cujas práticas são fundamentais para o avanço da ciência, em um contínuo processo dialético que não dissocia teoria e prática. No entanto, “[...] há mecanismos inerentes à instituição escolar que operam à margem ou inclusive contra a vontade consciente dos professores" (LERNER, 2002, p. 32). A formação docente, que não dissocia teoria e prática, não pode estar apartada da construção do Projeto Político-Pedagógico.

Freire e Macedo (2015, p. 11) nos provocam a pensar o processo de alfabetização de maneira mais consciente, mais crítica, sem perder de vista em nenhum momento a dialeticidade entre a objetividade e a subjetividade na educação libertadora. A formação crítica dos(as) docentes, conforme suas ideias “[...] significa sempre interpretar a própria interpretação, repensar os contextos, desenvolver múltiplas definições e tolerar ambiguidades, de modo que se possa aprender a partir da tentativa de resolvê-las" (p. 23).

A criança, quando chega à escola, possui diversos saberes que precisam ser identificados e compreendidos pelos(as) docentes. Como ser pensante e presente no mundo, mesmo na mais tenra idade já possui uma história e uma experiência de vida, ainda que limitada ao seu pequeno círculo sociocultural, e consegue comunicar-se, interpreta símbolos e imagens, pensa sobre o que está escrito e como se pode ler.

As ações de ler e escrever ocorrem em diferentes contextos, por isso mesmo, apenas conhecer as palavras, identificá-las e saber reproduzi-las não promovem aprendizagem significativa, podendo levar ao fracasso. 
Estudantes que são aprovados(as) ao final do terceiro ano, considerando como critério único a decodificação das palavras, por terem sido submetidos(as), ao longo dos anos iniciais, a situações de reprodução, de transcrição de palavras, frases e interpretações apenas de textos escolarizados, terão muitas dificuldades na continuidade dos estudos.

A alfabetização emancipadora, significativa, requer que os conteúdos escolares estejam vinculados à leitura de mundo, que antecede a leitura da palavra, e a aprendizagem desta promove outras leituras de mundo. O percurso da aprendizagem da leitura e da escrita promove nova leitura de mundo, para que as crianças sejam respeitadas e possam dizer sua própria palavra (FREIRE, 1987).

\section{A escola de tempo integral e a sua correlação com a educação integral e as políticas públicas}

Esse processo de alfabetização emancipadora proposta por Freire poderia se tornar significativo em escolas de tempo integral, em um ambiente singular, composto por pluralidades e em constante transformação.

Há muitas décadas, a escola de tempo integral tem sido projetada, e até colocada em prática, na história da educação no País, por meio de políticas públicas, como demonstram as ações empreendedoras de Anísio Teixeira.

Em sua administração, no Rio de Janeiro (1931-1935), Anísio Teixeira implementou a escola de tempo integral, com um turno regular e outro com "atividades propriamente sociais", conforme Dórea (2000, p. 2) e, como Secretário de Educação e Saúde do Estado da Bahia (1947-1951), deu continuidade ao seu "Projeto de Escola de Tempo Integral".

Após a ditadura militar, na gestão de Leonel Brizola, no Rio de Janeiro (1983-1987), foram criados os Centros Integrados de Educação Pública - idealizados por Darcy Ribeiro. Posteriormente, surgiram os Centros Integrados de Atenção à Criança e ao Adolescente (CIAC), no governo Collor (1990-1992), e os Centros de 
Atenção Integral à Criança e ao Adolescente (CAIC) no governo Itamar Franco (1992-1995).

$\mathrm{Na}$ cidade de São Paulo, os Centros Educacionais Unificados (CEU), criados na gestão de Marta Suplicy (2001-2004), dialogam com o conceito de cidade educadora, que entende a cidade como um território educativo, assim como seus diferentes espaços, tempos e atores.

O atual Plano Nacional de Educação (PNE), em vigência desde 2014, com metas a serem cumpridas até 2024, em sua "meta de número 6" propõe: "Oferecer educação em tempo integral em, no mínimo, 50\% das escolas públicas, de forma a atender, pelo menos, 25\% dos(as) alunos(as) da Educação Básica” (BRASIL, 2014). Dessa forma, discutir as ações e relações nesse ambiente significa lançar-se num grande e necessário desafio, compreendendo seus percursos e percalços no enfrentamento do fracasso na alfabetização.

No entanto, o PNE já problematiza o contexto em que essa educação será desenvolvida, considerando que ampliar a exposição das crianças e jovens às situações de ensino é bandeira fundamental na busca pela equidade e pela qualidade na educação, mas reconhecendo que a educação integral não é sinônimo apenas de mais tempo na escola. Aos estudantes matriculados nessa modalidade de ensino, é preciso propiciar múltiplas oportunidades de aprendizagem, por meio do acesso à cultura, à arte, ao esporte, à ciência e à tecnologia, com atividades planejadas em função de um Projeto Político-Pedagógico integrado e integrador.

Em 2010, o Decreto n. 7.083, que instituiu o "Programa Mais Educação", define como "integral" a jornada escolar com duração igual ou superior a sete horas diárias, durante todo o período letivo que o(a) estudante permanece na escola, ou em atividades escolares (BRASIL, 2010). Porém, se o aumento da jornada escolar, por si só, é insuficiente para garantir uma educação integral, quais as condições necessárias para promover a melhor qualidade do ensino e aprendizagem? Quem são os responsáveis por garantir as condições? 
É necessário esclarecer que não há a pretensão de respondermos a tais questionamentos, como se pudéssemos propor receitas prontas, tampouco acreditamos que fora da educação em tempo integral não se tenha condições favoráveis para o ensino. Mas nos propomos a provocar reflexões acerca dos desafios no interior da escola de tempo integral a partir do diálogo com os(as) profissionais que atuam na escola. Destacamos a complexidade dessa proposta, uma vez que estamos investigando em determinado contexto, com suas especificidades, e os resultados da investigação não podem ser simplesmente generalizados para outros contextos.

Há, no entanto, princípios básicos assumidos quando se propõe construir uma educação libertadora. Um desses princípios é a leitura crítica da realidade de nosso país, no qual a injustiça social atinge parcela significativa da população. Crianças oriundas de lares pobres, que vivem em ambientes precários, cujas famílias não tiveram acesso à educação escolar, precisam ser compreendidas em sua condição de vítimas desse sistema.

Segundo Arroyo (2012):

Mudar o nosso olhar: de visão histórica que os considera [humanos, crianças $e$ adolescente em formação] responsáveis como indivíduos ou como membros de coletivos sociais, étnicos, raciais, de gênero, campo, periferias, pichados em nossa cultura política como inferiores a serem salvos através da escola e de ações moralizadoras, para vermos como vítimas históricas de relações sociais, econômicas, políticas e culturais de dominação-subordinação-inferiorização. Essa mudança de olhar, de vulneráveis a vítimas, mudará todo programa e toda política socioeducativa, mudará nossa postura ética profissional (ARROYO, 2012, p. 40).

Nesse sentido, a centralidade dos programas que amparam a escola integral e seus Projetos Político-Pedagógicos está no direito das crianças a tempos-espaços mais dignos, como propõe Arroyo (2012), pois a vulnerabilidade social em que está submetida a infância e a juventude popular passa pela precariedade dos espaços, pela desigualdade social e pela desumanização do(s) tempo(s), sendo, dessa forma, obrigadas a viver nos limites humanos, no limite do exercício da liberdade e das opções éticas. 
Considerando diferenças tão evidentes em um país com as dimensões territoriais do Brasil, entendemos que uma relevante alternativa para enfrentar tal desafio seja a construção de um Projeto Político-Pedagógico que imprima a identidade da escola revelada em sua comunidade nas ações pedagógicas cotidianas, observando o contexto e as necessidades dessa coletividade e possa, a partir disso, planejar suas ações pedagógicas, levando em conta os diversos graus de aprendizagem dos(as) estudantes, valorizando suas produções, ideias e criatividade, por meio das artes, da cultura, das atividades físicas e tecnológicas.

A relação entre o micro e o macro, sempre em diálogo, é um compromisso adotado coletivamente com a intenção de assumir a responsabilidade da instrução de todos(as) os(as) estudantes, ou seja, apresenta-se como uma ação estratégica para um trabalho coletivo fundamentado teoricamente que possa enfrentar as dificuldades de aprendizagem.

À gestão pedagógica cabe liderar essa ação, sempre na perspectiva de coordenar o trabalho pedagógico que considere o ensino e a aprendizagem dos estudantes que frequentam a escola pública (CAMPOS, 2015).

Um currículo interdisciplinar pode proporcionar o desenvolvimento em sua unidade e em sua diversidade, em que a construção do conhecimento perpasse pelo trabalho coletivo, pela cultura da paz e do respeito, bem como pelo reconhecimento e acolhimento das diferenças dos estudantes, considerando a pesquisa, a análise dos saberes e a avaliação como processo em seus aspectos e princípios pedagógicos.

\section{Desenvolvimento da pesquisa}

A pesquisa de campo, de natureza qualitativa, fundamentou-se em André (2001), Lima e Mioto (2007), Minayo (1996), Minayo e Sanches (1993) e Richardson (1999). Foram realizadas entrevistas reflexivas, com base em Manzini (2012) e Szymanski (2002), em uma escola pública de período integral, localizada em um municí- 
pio da Grande São Paulo. Participaram da pesquisa a coordenadora pedagógica e três docentes do ensino fundamental, envolvidos(as) com o processo de alfabetização das crianças matriculadas nos três primeiros anos. Destacamos que, por questões éticas, foi mantido em sigilo o nome da escola e de todos os(as) entrevistados(as).

O convite aos(às) profissionais da escola teve a intenção de dar voz a quem trabalha na instituição, possibilitando a expressão de suas ideias e percepções sobre quais são os fatores que, em suas perspectivas, interferem no processo de alfabetização e, na sequência, problematizar tais fatores a partir da concepção de alfabetização fundamentada em Emilia Ferreiro e Paulo Freire.

O objetivo central da pesquisa foi identificar e analisar as percepções desses(as) profissionais sobre os fatores que podem levar à reprovação de estudantes e às dificuldades no prosseguimento dos estudos, no contexto da escola de período integral, e suas estratégias para enfrentar pedagogicamente o problema. Os objetivos específicos colocados são:

1. identificar o conceito de alfabetização dos(as) profissionais selecionados(as) para a pesquisa;

2. conhecer suas estratégias didáticas para alfabetizar e lidar com as dificuldades dos(as) alunos(as);

3. contribuir, a partir das análises das entrevistas, com a ampliação dos debates sobre o objeto de investigação.

O município da Grande São Paulo onde se localiza a escola possui um alto Índice de Desenvolvimento Humano (IDH), correspondente a 0,862 , condição que destacou esse município em $1^{\circ}$ lugar no País, de acordo com dados do Instituto de Pesquisas Econômicas Avançadas (IPEA), em 2010 (IBGE, 2010).

A classificação da escola, conforme o IDH referido, apresentou-se como um diferencial para a determinação dos critérios de seleção do lócus da pesquisa, pois, no contexto econômico em que a instituição realiza o seu trabalho de alfabetização, poderíamos supor que as crianças teriam melhores possibilidades de acesso à cultura letrada, contribuindo, dessa maneira, com o êxito na alfa- 
betização no período proposto pelo Plano Nacional de Educação (PNE), Lei n. 13.005/2014, "Meta 5", ou seja, nos três primeiros anos do ensino fundamental (BRASIL, 2014).

A condição mencionada, teoricamente, facilitaria o cumprimento da "Meta 5" do PNE (100\% das crianças alfabetizadas no período), no entanto, de acordo com dados iniciais levantados na referida escola, quando ocorreu a investigação, constatou-se que havia crianças reprovadas ao final do terceiro ano do ensino fundamental, compondo respectivamente os seguintes percentuais de retenção: 8,73\% (2017), 4,46\% (2016) e 7,69\% (2015). Tais dados motivaram a busca das razões dessas reprovações, bem como os questionamentos sobre a possível relação com a alfabetização.

Para a abordagem dos sujeitos da pesquisa, considerando que as entrevistas ocorreram antes da pandemia da COVID-19, foi utilizada a técnica de entrevista presencial gravada, posto que o contato pessoal, frente a frente, é uma situação de interação humana em que as percepções do outro, suas expectativas, sentimentos e preconceitos são mobilizados e podem contribuir com a reflexão crítica do tema pesquisado.

Assim, conforme os enunciados teóricos apresentados, foram desenvolvidas quatro entrevistas reflexivas (SZYMANSKI, 2002), de forma individual, com abordagem qualitativa como referência, por abarcar um conjunto heterogêneo de perspectivas e análises, buscando a compreensão das questões postas a partir das pessoas que atuam e trazem o olhar "de dentro" do contexto dessa escola.

A opção pela entrevista com os(as) profissionais convidados(as) deveu-se ao potencial que essa técnica oferece, e mostrou-se, na prática, como um procedimento apropriado - condição constatada efetivamente durante o desenvolvimento do trabalho de campo. Esse instrumento forneceu, ainda, elementos para compreender e problematizar a grande complexidade inerente ao tema proposto, lançando mão, como afirma André (2001), de um vasto arsenal de enfoques e percepções capazes de proporcionar maior entendimento das questões a serem investigadas neste trabalho. 
De forma complementar, Minayo (1996) afirma que, ao mesmo tempo em que existe a representatividade da fala na entrevista, há os ocultamentos e distorções inevitáveis. Assim, o movimento reflexivo que a narração exige contribui para colocar o(a) entrevistado(a) frente ao pensamento organizado, de uma maneira inédita até para si mesmo(a).

Além disso, durante a entrevista, algumas situações são passíveis de serem observadas pelo(a) entrevistador(a), a partir da manifestação do(a) entrevistado(a) e de suas posturas mais espontâneas ou rígidas assumidas no evento. Ao mesmo tempo, a entrevista reflexiva fornece liberdade de expressão ao(à) entrevistado(a) para construir suas respostas, de acordo com seu ritmo e raciocínio.

A flexibilidade ofertada pelo instrumento da entrevista permite ao(à) entrevistado(a) ter maior confiança nas respostas, à medida que concede ao(à) pesquisador(a) a reflexão sobre a sua fala. $\mathrm{O}(\mathrm{a})$ entrevistador(a), ao expressar compreensão em relação ao discurso obtido na entrevista, pode submeter esse seu entendimento ao(à) entrevistado(a) como uma forma de aprimorar a fidedignidade das respostas, ou, como afirma Mielzynska (1998, p. 132 apud SZYMANSKI, 2002, p. 14-15), cuja concepção vale reiterar: assegurar-se "que as respostas obtidas sejam verdadeiras - isto é, não influenciadas pelas condições de aplicação e conteúdo do instrumento".

Cabe esclarecer que no processo de realização das entrevistas, de forma particularizada pelo discurso de cada entrevistado(a), surgiram e foram respondidas questões complementares que ampliaram o sentido das concepções, opiniões, percepções e representações dos participantes em relação ao desdobramento do tema central abordado. Tomamos o cuidado de conversar pessoal e individualmente com cada um(a), para explicar os objetivos da pesquisa e os cuidados que já tinham sido tomados, assim como as autorizações obtidas. Todos os encontros transcorreram em um clima assertivo e participativo, sem intercorrências.

A escuta, as transcrições e as análises das entrevistas realizadas basearam-se na Metodologia de Análise de Conteúdo, formulada por 
Franco (2008, p. 14), que se apresenta como “[...] um procedimento de pesquisa que se situa em um delineamento mais amplo da comunicação e tem como ponto de partida a mensagem". A mensagem pode expressar-se de forma verbal, gestual, silenciosa, figurativa ou documental, mas, sempre, plena de significados e sentidos cognitivos, afetivos, valorativos e ideológicos do(a) participante, a serem interpretados pelo(a) pesquisador(a), em diálogo com o entrevistado.

\section{A voz dos(as) entrevistados(as) na prática}

Em relação aos dados e informações obtidas na pesquisa, por meio das entrevistas, o desafio que se apresentou foi buscar os conhecimentos e as experiências dos(as) participantes sobre alfabetização, bem como suas rotinas, expectativas e estratégias didáticas, a fim de identificar suas percepções sobre as causas das dificuldades na alfabetização e reprovação dos estudantes, contribuindo com elementos para o debate do presente objeto de investigação.

A pesquisa foi organizada em eixos temáticos, conforme critério já utilizado por ocasião das entrevistas, de modo a analisarmos os discursos dos(as) entrevistados(as), para aprofundamento do estudo das questões propostas neste trabalho. Vale ressaltar que a pesquisa completa possui seis eixos temáticos, mas pelos limites deste artigo, destacaremos apenas alguns aspectos relevantes nas manifestações dos(as) docentes e da coordenadora pedagógica.

\section{Identificar como os(as) entrevistados(as) compreendem sua prática docente}

As questões desse eixo, apresentadas aos(às) entrevistados(as), reuniram uma série de aspectos importantes relacionados à prática docente: seu planejamento, organização e estratégia; os relacionamentos entre os docentes e as famílias dos(as) alunos(as); a condição em que as crianças chegam à sala de aula, com qual bagagem de experiência e se possuem uma vida cultural à parte das atividades propostas na escola; a interação entre os(as) docentes do turno regular e os(as) docentes das oficinas. Por se tratar de uma 
escola de tempo integral, cuja matriz curricular é complementada, tais disciplinas são chamadas de oficinas.

Em suas respostas, os(as) professores(as) relataram que recebem formações e materiais que devem aplicar, revelando uma concepção formativa mais voltada à prescrição, que não coloca os docentes na condição de participantes do processo formativo, para que possam dialogar, problematizar, questionar e construir conhecimentos.

Quando um(a) dos(as) entrevistados(as) aborda a necessidade de reunião com os pares, anseia por discutir o trabalho pedagógico a partir da realidade da escola. Não é fácil trabalhar com a diversidade de conhecimentos, a diversidade de hipóteses de leitura e escrita, a diversidade social e cultural. É importante ressaltar que os(as) professores(as) clamam por formações que articulem a teoria com sua prática docente.

Nos discursos dos(as) três docentes observa-se a diversidade de experiências e conhecimentos que os(as) alunos(as) apresentam no início do ano letivo, o que reforça a presença das características individuais e a necessidade de se considerar essas diferenças, principalmente nas intervenções e mediações do cotidiano.

No contraponto das falas dos(as) entrevistados(as), é evidenciada uma dicotomia entre o que deve ser realizado em termos de planejamento e semanário, conforme as diretrizes formuladas pela escola e pelos programas e políticas, e aquilo que efetivamente se constata, na prática, em sala de aula. Essa afirmação é sustentada pelo discurso da Coordenadora Pedagógica (CP), que cita alguns exemplos no decorrer da entrevista que comprovam a existência de falhas/deficiências graves de planejamento e uso do semanário no grupo de docentes.

Ao mesmo tempo em que a CP realiza uma crítica ao corpo docente, devido ao fato de os professores e as professoras não seguirem os propósitos estabelecidos para cada ano/série, por não utilizarem adequadamente os materiais fornecidos pelos programas de educação, ela sente-se impotente diante da situação, que consi- 
dera inapropriada e prejudicial para a formação dos(as) alunos(as), pois é excluída ou não consegue se encaixar e fazer parte do grupo para poder orientar/coordenar o trabalho docente.

Também é evidente a ausência de fundamentos consistentes para o trabalho dos(as) professores(as), para a organização de aulas e atividades, para o uso de recursos, sistemas e materiais disponíveis, prevalecendo, não raras vezes, a opinião ou um esquema pessoal, que nem sempre se mostra adequado, como comentou a Coordenadora Pedagógica.

\section{Os problemas e dilemas do ambiente escolar na voz da Coordenadora Pedagógica (CP)}

À Coordenadora Pedagógica (CP) foram apresentadas algumas questões diferenciadas em relação àquelas propostas aos(às) docentes, em função do seu cargo e responsabilidades na escola, de forma a identificar o seu olhar referente às rotinas, às atividades oferecidas pelos(as) professores(as) e outros assuntos de interesse. A Coordenadora Pedagógica foi inquirida sobre a diferença do exercício de sua função entre escolas regulares e escolas de tempo integral.

Para a entrevistada, o fato de a criança estudar em uma escola regular permite que ela tenha mais tempo de convivência com a sua família e, ainda que enfrente dificuldades, pode fornecer-lhe conforto e atenção. Portanto, no entendimento da Coordenadora, a criança vai para a escola regular mais descansada e com melhor disposição para aprender.

$\mathrm{Na}$ escola de tempo integral, segundo a $\mathrm{CP}$, isso não ocorre e, além do mais, "falta oxigenação" no ambiente escolar e na relação da criança com o(a) professor(a), devido ao grande tempo de permanência e convivência na instituição, o que torna o processo inteiro muito cansativo para todos, inclusive para ela, referindo-se à rotina da escola de tempo integral ser muito pesada e diferente daquela da escola regular. É importante ressaltar que a resposta da CP coloca em dúvida os benefícios e a validade da escola de tempo integral nos moldes em que ela opera hoje no âmbito da educação. 
No eixo temático - compreender a concepşão de alfabetização -, foi apresentada à $\mathrm{CP}$ uma pergunta específica: "Considerando que a política implantada com o ensino fundamental de nove anos é alfabetizar até o final do terceiro ano, quando foi solicitado aos(às) professores(as) que assumissem esses anos iniciais, foi requerida também experiência para atuar com alfabetização? O que pensa sobre isso?”.

De acordo com a CP, a experiência em alfabetização é imprescindível para que os(as) professores(as) assumam as turmas dos três primeiros anos do ensino fundamental I e recebam a atribuição das aulas. Porém, mesmo citando exemplos e teóricos da educação, a visão da CP sobre a formação dos(as) professores(as) para a alfabetização mostra-se vaga, dispersa, pouco fundamentada e também não muito objetiva, mas ela reconhece que essa formação não é totalmente adequada, como em um passado recente, quando os(as) professores(as), antes do curso de Pedagogia, iniciavam a sua formação a partir do Magistério, que, segundo sua percepção, fornecia uma base muito mais sólida para entender o desenvolvimento cognitivo da criança e sua forma de aprender.

No que se refere aos ritmos de aprendizagem na alfabetização, a CP foi questionada se os(as) docentes sob a sua coordenação percebem a diversidade de saberes dos(as) alunos(as) e se sabem como lidar com isso no dia a dia, e como ela tem encadeado as discussões a respeito.

$\mathrm{Na}$ visão da $\mathrm{CP}$, os(as) professores(as) não têm muito conhecimento da diversidade dos ritmos de aprendizagem de alfabetização dos(as) discentes, fazendo uso, não raras vezes, de material padrão ou utilizando didáticas unificadas para os(as) alunos(as) com níveis diferenciados de aprendizagem. E qualquer alteração de postura e de procedimento, segundo a entrevistada, é rebatida com a alegação da falta de tempo, como a própria CP também afirma em sua função de atender e coordenar o trabalho dos(as) professores(as) nesse sentido.

Questionada sobre a forma como os(as) professores(as) organizam as atividades de leitura que são propostas para os(as) 
alunos(as), a CP informa que não desenvolve acompanhamento sistemático sobre os textos apresentados a eles e elas, mas identifica falhas nas atividades docentes em relação à leitura, mediante um ou outro caso observado, e ela também questiona a qualidade literária dos materiais fornecidos às crianças, ou seja, livros e textos com qualidade duvidosa.

Como afirma a $\mathrm{CP}$, esse acompanhamento não acontece, por ela ser vista como uma oponente dos(as) professores(as), e não como uma profissional que pode contribuir com o trabalho coletivo, em função da sua experiência como docente e alfabetizadora.

\section{Considerações finais}

O tema escolhido para a pesquisa apresenta-se como uma questão contemporânea que envolve inúmeros aspectos, situados tanto no âmbito da educação nacional, quanto nas implicações sociais profundas, que necessitam ser analisados, dada a importância outorgada à educação como fator-chave para a cidadania e desenvolvimento de um país.

Os conceitos de alfabetização dos(as) participantes da pesquisa apresentam modulações e diferenciações acentuadas, como pôde ser observado em suas respostas. Os(as) docentes consideram que a reprovação é normal, e até benéfica em alguns casos, para que as crianças tenham outra chance de aprender, afirmando, ainda, que o fato de estarem em escola de período integral não significa que elas serão automaticamente aprovadas.

Foi constatada a carência de um nível organizacional estruturado e consistente, que seja formalizado, documentado e divulgado para o conhecimento de todos(as) os(as) docentes da instituição, pois não há espaços planejados para o trabalho coletivo, fundamentado em princípios éticos das relações entre docentes, coordenação pedagógica, famílias e alunos(as).-

Em 2018, no planejamento inicial, os professores e professoras receberam um "Manual de Apoio aos Professores", em que constam informações administrativas, a exemplo do calendário escolar, 
principais saídas pedagógicas, atribuições dos docentes (uso dos espaços, relógio de ponto, faltas, atrasos e atestados), avaliação escolar (instrumentos do trimestre, modelos, tipo de letra, cabeçalho, cálculo de médias), recados gerais, ou seja, questões de cunho administrativo. Sendo assim, faltaram diretrizes e encaminhamentos coletivamente discutidos, tais como:

a) fundamentos didático-pedagógicos para a elaboração do planejamento de aulas, visto que cada profissional entrevistado(a) utiliza um critério ou sistema pessoal, de forma empírica, não sistematizada e sem respaldo teórico;

b) tratamento apropriado para a transição dos(as) alunos(as) a cada ano/série do ensino fundamental I, por meio de relatório, ou de outro instrumento específico a ser elaborado, e que seja disponibilizado e facilmente consultado, para posicionar os(as) docentes em relação ao estágio de alfabetização atingido pelos(as) alunos(as) que farão parte da sua turma. Esse é um componente importante para que as ações necessárias, caso a caso em suas especificidades, sejam implementadas, e para que o(a) professor(a) do novo ano/série esteja preparado(a) para receber as crianças e já munido(a) das informações;

c) sistematização de reuniões e encontros pedagógicos, com frequências definidas e apropriadas às demandas da escola pesquisada, pois foi constatada a ausência de contato e diálogo aberto entre os atores envolvidos na alfabetização. Todos(as) os(as) entrevistados(as) afirmam não haver espaço-tempo de reuniões para organizar procedimentos e projetos, tampouco de ordem pedagógica, para nortear os critérios e meios necessários a uma educação de qualidade;

d) definição de contrato de trabalho, deixando claro o papel da coordenação e da equipe docente, que é essencial para os relacionamentos interpessoais, para que haja a possibilidade de um trabalho em equipe harmonioso e bem-sucedido, como também para o debate respeitoso sobre 
qualquer mudança a ser realizada na instituição, superando as resistências em relação à Coordenadora Pedagógica (CP), que se vê excluída, ou à parte do grupo de profissionais;

e) divulgação e estudos das legislações pertinentes às políticas e programas de educação, para que sejam do conhecimento de todos e para que todos possam refletir sobre o teor das propostas políticas, considerando o contexto da escola;

f) implementar um sistema de gestão transparente e democrático, que permita a participação de todos, receba as críticas positivas, promova a reflexão sobre as práticas, trâmites e atividades exercidas, e que discuta assertivamente sobre metas, objetivos e projetos futuros.

De acordo com as análises realizadas, as concepções de alfabetização não estão alinhadas. Os(as) entrevistados(as) citam autores e propostas que não se articulam. Em alguns trechos das entrevistas, é possível identificar a alfabetização como aquisição de um código, o que se contrapõe às proposições teóricas de Ferreiro, que trata do sistema alfabético a ser aprendido de forma processual e contínua, pois se refere a uma forma de representação da linguagem. Tomando como base suas próprias concepções de alfabetização, os(as) docentes assumem estratégias de ensino diferenciadas para o trabalho com os(as) alunos(as) que não alcançaram os objetivos propostos.

Segundo os(as) participantes da pesquisa, a permanência dos(as) alunos(as) por mais tempo na escola e com maior diversidade de atividades não se apresenta como garantia de aprendizagem e aprovação, apesar de ser esse um dos objetivos da escola em tempo integral, propulsora da educação integral, em seu projeto inicial, ou seja, garantir uma educação de qualidade e o sucesso escolar.

Compreendemos que o sistema de ensino apresenta uma relação dialética com a sociedade e, ao mesmo tempo em que tem função implicitamente reprodutivista, também transforma esse corpo social e sua cultura. Entendemos também que os momentos de 
diálogos pedagógicos e as formações em serviço, da forma como se propõem, não são suficientes para uma mudança na proposta pedagógica. Conforme declara Lerner (2002):

[...] a mudança da proposta didática não depende só das vontades individuais dos professores - por melhor capacitados que eles sejam - significa aceitar que, além de continuar com os esforços de capacitação, será necessário estudar os mecanismos ou fenômenos que ocorrem na escola e impedem que todas as crianças se apropriem dessas práticas sociais que são a leitura e a escrita (LERNER, 2002, p. 33).

De acordo com os relatos obtidos nas entrevistas, observa-se que os objetivos e intencionalidades propostos nas políticas públicas e nas bases teóricas dos estudiosos e especialistas pesquisados ainda não atingiram a realidade da escola analisada neste trabalho. Percebemos que falta interação entre os(as) professores(as) da mesma série/ano, entre os(as) de séries/anos diferentes e entre os(as) do turno regular e os(as) de oficina, situação que interfere, diretamente, na aprendizagem dos(as) estudantes.

Reiteramos, enfim, que uma educação de qualidade se faz em uma escola de qualidade, com processos de qualidade, sejam eles pedagógicos, administrativos, mas, sobretudo, com relações humanas críticas, reflexivas e éticas.

Temos a clareza das limitações do presente estudo, ao nos restringirmos a uma única instituição de ensino de tempo integral da região do Grande ABC, em São Paulo, porém, o trabalho desenvolvido, mesmo constituindo-se como sinalizador de um microuniverso, serve-nos de parâmetro para a realização de pesquisas mais amplas, que envolvam um número maior de escolas de tempo integral situadas em outros municípios e com mais participantes, de modo a expandir as análises sobre o tema e seus desdobramentos, para estabelecer um diálogo entre as instituições de ensino da região, seus Projetos Político-Pedagógicos, suas dificuldades, estratégias, fracassos e sucessos no campo da alfabetização dos(as) alunos(as), bem como para dar vez e voz a outros(as) tantos(as) docen- 
tes e coordenadores(as) pedagógicos(as) que ecoam no ambiente e na realidade escolar brasileira.

\section{Referências}

ANDRÉ, Marli. Pesquisa em educação: buscando rigor e qualidade. Cadernos de Pesquisa, n. 113, p. 51-64, jul. 2001. Disponível em: https://doi.org/10.1590/ S0100-15742001000200003. Acesso em: 15 out. 2021.

ARROYO, Miguel. O direito a tempos-espaços de um justo e digno viver. In: MOLL, Jaqueline (org.). Caminhos da educação integral no Brasil: direito a outros tempos e espaços educativos. Porto Alegre: Penso, 2012.

BRASIL. Decreto 7.083, de 27 de janeiro de 2010. Dispõe sobre o Programa Mais Educação. Brasília: Presidência da República, Casa Civil, 2010. Disponível em: http://www.planalto.gov.br/ccivil_03/_ato2007-2010/2010/decreto/d7083. htm. Acesso em: 15 out. 2021.

BRASIL. Lei $\mathbf{n}^{\circ}$ 13.005, de 25 de junho de 2014. Aprova o Plano Nacional de Educação - PNE e dá outras providências. Subchefia para Assuntos Jurídicos. Brasília: Presidência da República, Casa Civil, 2014. Disponível em: http://www.planalto. gov.br/ccivil_03/_ato2011-2014/2014/lei/113005.htm. Acesso em: 15 out. 2021.

CAMPOS, Elisabete F. Esteves. A coordenação pedagógica em questão: diálogos nos círculos de debate. Jundiaí: Paco Editorial, 2015.

CHARLOT, Bernard. Relação com o saber e com a escola entre estudantes de periferia. Tradução de Neide Luzia de Resende. Cadernos de Pesquisa, São Paulo, n. 97, p. 47-73, maio 1996. Disponível em: http://publicacoes.fcc.org.br/index. php/cp/article/view/803/814. Acesso em: 20 out. 2021.

DÓREA, Célia Rosângela Dantas. Anísio Teixeira e as políticas de edificações escolares no Rio de Janeiro (1931-1935) e na Bahia (1947-1951). REUNIÃO ANUAL DA ANPED, 23., 2000, Caxambu/MG. Anais [...], Caxambu: ANPEd, 2000. Disponível em: http://23reuniao.anped.org.br/textos/0206p.PDF. Acesso em: 15 out. 2021.

FERREIRO, Emilia. Reflexões sobre alfabetização. 25. ed. São Paulo: Cortez Editora, 2010.

FERREIRO, Emilia; TEBEROSKY, Ana. Psicogênese da língua escrita. Tradução de Diana Myriam Lichtenstein, Liana Di Marco e Mário Corso. Porto Alegre: Artes Médicas, 1986. 
FRANCO, Maria Laura P. B. Análise de conteúdo. 3. ed. Brasília: Liber Livro, 2008.

FREIRE, Paulo. Pedagogia do oprimido. Rio de Janeiro: Paz e Terra, 1987.

FREIRE, Paulo; MACEDO, Donaldo. Alfabetização: leitura do mundo, leitura da palavra. 7. ed. Rio de Janeiro: Paz e Terra, 2015.

GARCIA, Roosevelt. A inesquecível cartilha Caminho Suave - famoso livro de alfabetização teve quase 40 milhões de exemplares em mais de 100 edições. Veja São Paulo on-line, Caderno Cultura \& Lazer, edição 30 agosto 2017. Disponível em: https://vejasp.abril.com.br/blog/memoria/a-inesquecivel-cartilha-caminho-suave/. Acesso em: 14 out. 2021.

GUMPERZ, Jenny C. A construção social da alfabetização. Porto Alegre: Artes Médicas, 1991. p. 58-82.

IBGE - INSTITUTO BRASILEIRO DE GEOGRAFIA E ESTATÍSTICA. Índice de Desenvolvimento Humano, 2010. Rio de Janeiro: IBGE, 2010.

LERNER, Délia. Ler e escrever na escola: o real, o possível e o necessário. Tradução Ernani Rosa. Porto Alegre: Artmed, 2002.

LIMA, Telma Cristiane Sasso; MIOTO, Regina Célia Tamaso. Procedimentos metodológicos na construção do conhecimento científico: a pesquisa bibliográfica. Revista Katál, Florianópolis, v. 10, n. esp., p. 37-45, 2007. Disponível em: https://www.scielo.br/j/rk/a/HSF5Ns7dkTNjQVpRyvhc8RR/?format=pdf. Acesso em: 18 out. 2021.

MANZINI, Eduardo José. Considerações sobre a transcrição de entrevistas. In: MANZINI, Eduardo José. A entrevista como instrumento de pesquisa em Educação e Educação Especial: uso e processo de análise. Tese (Livre-docência em Educação) - Faculdade de Filosofia e Ciências, Unesp, Marília, SP, 2012. Disponível em: https://transcricoes.com.br/wp-content/uploads/2014/03/texto_orientacao_transcricao_entrevista.pdf. Acesso em: 19 out. 2021. 17 p.

MIELZYNSKA, Jadwiga. A construção e a aplicação de questionários na pesquisa em Ciências Sociais. Revista do Programa de Estudos Pós-Graduados PUCSP, São Paulo, v. 6, p. 1-21, $1^{\circ}$ sem. 1998. Disponível em: https://revistas.pucsp. br/psicoeduca/article/view/42894. Acesso em: 18 out. 2021.

MINAYO, Maria Cecília de Souza. O desafio do conhecimento: pesquisa qualitativa em saúde. 4. ed. São Paulo: Hucitec, 1996. 
MINAYO, Maria Cecília de Souza; SANCHES, Odécio. Quantitativo-qualitativo: oposição ou complementaridade? Caderno de Saúde Pública, Rio de Janeiro, v. 9, n. 3, p. 239-262, jul./set., 1993. Disponível em: http://www.scielo.br/pdf/csp/ v9n3/02.pdf. Acesso em: 30 set. 2021.

RICHARDSON, Roberto Jarry. Pesquisa social: métodos e técnicas. São Paulo: Atlas, 1999.

SANTOS, Marla; ANDRETTA, Cyntia. "É preciso novos ambientes educativos", diz professor. Entrevista com o reitor honorário da Universidade de Lisboa, António Nóvoa. Digitais PUC Campinas, 31 de agosto de 2018. Disponível em: https://digitais.net.br/2018/08/digitais-campinas-diz-antonio-novoa-doutor-em-educacao/. Acesso em: 14 out. 2021.

SZYMANSKI, Heloísa (org.) A entrevista na pesquisa em educação: a prática reflexiva. Brasília: Liber Livros, 2002. 